\title{
MEMBANDINGKAN METODE SIMPLE ADDICTIVE WEIGHTING (SAW) DAN MULTIFACTOR EVALUATION PROCESS (MFEP) DALAM PENENTUAN JURUSAN SMA NEGRI 10 PADANG
}

\author{
Deny Suyandi, Rini Sovia, Aulia Fitrul Hadi \\ Universitas Puta Indonesia YPTK Padang \\ E-mail: ${ }^{1)}$ deny.yandi11@gmail.com ${ }^{3)}$ rini_sovia4ymail.com ${ }^{3)}$ fitrulhadi@upiyptk.ac.id
}

\begin{abstract}
Abstrak
Decision support system is a combination of individual intelligence sources with the ability of components to improve the quality of decisions. Decision support systems are also computer-based information systems for management decision-making that deal with semi-structured problems. With a decision support system makes it easier for us to determine the decisions for majors of high school students. Because the determination of this department is very influential with the future of students. So from that the author conducted this study to facilitate students in determining majors. So that these two methods can be compared and find the best results in making decisions about the majors of high school students.
\end{abstract}

Keywords: Decision Support System, Multifactor Evaluation Process, Simple Additive Weighting

\section{Pendahuluan}

\section{a) Latar Belakang}

Sistem pendukung keputusan merupakan penggabungan sumber-sumber kecerdasan individu dengan kemampuan komponen untuk memperbaiki kualitas keputusan. Sistem pendukung keputusan juga merupakan sistem informasi berbasis komputer untuk manajemen pengambilan keputusan yang menangani masalah-masalah semi terstruktur (Ahmad Khaidir, 2014).[1]

Sistem pendukung keputusan dapat meningkatkan efektifitas pengambilan keputusan, serta mengurangi kebutuhan akan pelatiha, peningkatan kontrol manager, memfasilitasi komunikasi, mengurangi usaha yang harus dikerjakan pengguna, mengurangi biaya dan memberikan banyak piliha dalam pengambilan keputusan.

Dengan adanya beberapa penjelasan diatas, maka penulis memilih judul "MEMBANDINGKAN METODE SIMPLE ADDICTIVE WEIGHTING (SAW) DAN MULTIFACTOR EVALUATION PROCESS (MFEP) DALAM PENENTUAN JURUSAN SMA NEGRI 10 PADANG" yang diharapkan dapat memberikan solusi efektif dalam pengambilan keputusan.

\section{b) Identifikasi Masalah}

Dalam penelitian ini muncul beberapa permasalahan, yang dirumuskan sebagai berikut:

1. Bagaimana cara menentukan jurusan bagi siswa Sekolah Menengah Atas yang tepat?

2. Bagaimana analisa sistem pendukung keputusan untuk menentukan jurusan di Sekolah Menengah Atas?

3. Bagaimana mengimplementasikan sebuah sistem penentuan jurusan di Sekolah Menengah Atas?

4. Bagaimana merancang aplikasi sistem pendukung keputusan agar dapat membantu dalam menentuan jurusan siswa Sekolah Menengah Atas? 


\section{Landasan Teori}

\subsection{Perangkat Lunak}

Sistem perangkat lunak berarti sebuah sistem yang memiliki komponen berupa perangkat yang memiliki hubungan satu sma lain untuk memenuhi kebutuhan pelanggan (Rosa A.S dan Shalahuddin, 2013).

\subsubsection{Rekayasa Perangkat Lunak}

Rekayasa perangkat lunak (Software Engineering) merupakan pembangunan perangkat lunak dengan menggunakan prinsip rekayasa atau konsep ekayasa dengan tujuan menghasilkan perangkat lunak yang bernilai ekonomis yang dipercaya dapat bekerja secara efisien menggunakan mesin. Tak jarang pearangkat lunak yang dibuat pada akhirnya tidak digunakan karena tidak sesuai dengan kebutuhan pelanggan bahkan karena permasalahan non-teknis seperti keinginan pemakai perangkat lunak (user) untuk mengubah cara kerja dari manual ke otomatis, atau ketidakmampuan user menggunakan komputer (Rosa A.S dan Shalahuddin, 2013).

\subsection{Unified Modeling Language}

Unified Modeling Language (UML) hanya berfungsi untuk melakukan pemodelan. Jadi Unified Modeling Language (UML) tidak terbatas pada metode tertentu, meskipun pada kenyataannya Unified Modeling Language (UML) paling banyak digunakan pada metodologi berorientasi objek (Rosa A.S dan Shalahuddin, 2013).

\subsection{Sistem Pendukung Keputusan}

Sistem pendukung keputusan merupakan penggabungan sumber-sumber kecerdasan individu dengan kemampuan komponen untuk memperbaiki kualitas keputusan. Sistem pendukung keputusan juga merupakan sistem informasi berbasis komputer untuk manajemen pengambilan keputusan yang menangani masalah-masalah semi terstruktur (Ahmad Khaidir, 2014).

\section{$2.4 \quad$ Multifactor Evaluation Process}

Multifactor Evaluation Process (MFEP) merupakan suatu metode yang memecahkan suatu situasi yang kompleks tidak terstruktur, kedalam bagian-bagian komponennya. Metode Multifactor Evaluation Process (MFEP) merupakan metode pengambilan keputusan yang melakukan pertimbangan subjektif dan intuitif terhadap faktor yang dianggap penting. Pertimbangan itu berupa pemberian bobot (weighting system) terhadap faktor-faktor yang dianggap penting.

\subsection{Simple Addictive Weighting}

Dalam jurnal INTENSIF Vol 1 No. 2 tahun 2017 (ISSN : 2580 - 409X) Metode Simple Addictive Weighting ( $S A W$ ) membutuhkan proses normalisasi matriks keputusan $\mathrm{X}$ ke dalam skala yang dapat diperbandingkan dengan semua rating alternatif yang ada. Skor 
total untuk alternatif deiperoleh dengan menjumlahkan seluruh hasil perkalian antara rating dan bobot tiap atribut.

\section{Metodologi}

Kerangka penelitian adalah urutan dari kegiatan-kegiatan yang akan dilakukan dalam melakukan peenelitian. Kerangka penelitian bertujuan untuk membantu penulis dalam melakukan penelitian, sehingga tujuan dari penelitian dapat tercapai dengan baik dan mudah dipahami oleh peulis. Urutan kerangka penelitian disusun secara sistematis sehingga menjadi pedoman bagi penulis untuk menyelesaikan permasalahan yang diteliti oleh penulis. Berikut adalah kerangka penelitian yang dibuat oleh penulis :

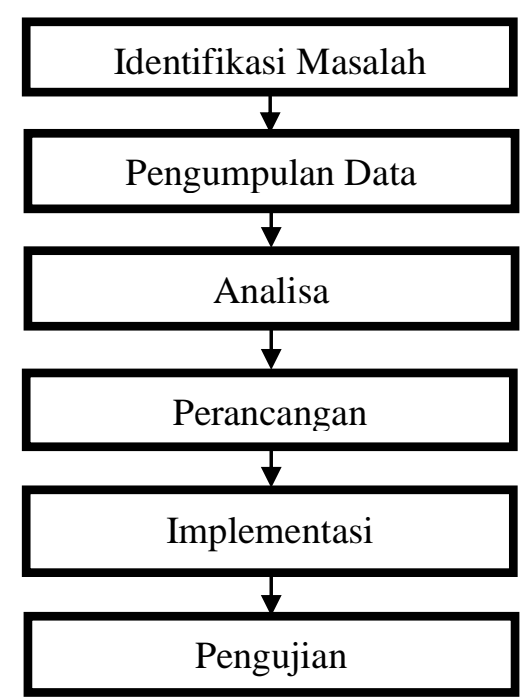

Gambar 3.1 Kerangka Kerja Penelitian

\section{Analisa}

Tahapan analisa data merupakan tahapan yang penting dalam pengembangan sebuah sistem, karena pada tahap ini terdapat kegiatan evaluasi kinerja, identifikasi masalah yang ada, rancangan sistem dan langkah-langkah yang dibutuhkan untuk perancangan yang diinginkan sampai pada analisa yang diharapkan.

Penelitian ini menggunakan bahasa program PHP sebagai alat bantu untuk pengambilan keputusan. Perancangan pada analisa data ini terdiri dari analisa data faktor beserta bobotnya.

\subsection{Perhitungan Metode Multifactor Evaluation Process}

Untuk melakukan proses perhitungan dibutuhkan rumus pencarian sebagai berikut:

Perhitungan nilai bobot evaluasi

Nbe $=$ Nbf $x$ Nef

Keterangan :

Nbe $\rightarrow$ Total Nilai Evaluasi

$\mathrm{Nbf} \rightarrow$ Nilai Bobot Evaluasi

$\mathrm{Nef} \rightarrow$ Nilai evaluation Faktor

Perhitungan total nilai evaluasi

Tne $=$ Nbe1 + Nbe $2+$ Nbe3 $\ldots$.

Keterangan : 


\author{
Tne $\rightarrow$ Total Nilai Evaluasi \\ Nbe $\rightarrow$ Total Nilai Evaluasi
}

Tabel 4.1 Tabel Perhitungan Siswa 1

\begin{tabular}{|c|c|c|c|c|}
\hline Faktor & Bobot Faktor & & Evaluasi faktor & Bobot Evaluasi \\
\hline Nilai UN IPA & 0.6 & $\mathrm{X}$ & 80 & 48 \\
\hline Tes Psikologi & 0.3 & $\mathrm{X}$ & 60 & 22,5 \\
\hline Minat & 0.1 & $\mathrm{X}$ & 0 & 0 \\
\hline Total & 1 & & & 70,5 \\
\hline
\end{tabular}

Tabel 4.2 Evaluasi Untuk Siswa 2

\begin{tabular}{|c|c|c|c|c|}
\hline Faktor & Bobot Faktor & & Evaluasi faktor & Bobot Evaluasi \\
\hline Nilai UN IPA & 0.6 & $\mathrm{X}$ & 60 & 36 \\
\hline Tes Psikologi & 0.3 & $\mathrm{X}$ & 80 & 24 \\
\hline Minat & 0.1 & $\mathrm{X}$ & 60 & 6 \\
\hline Total & 1 & & & 66 \\
\hline
\end{tabular}

Nilai evaluasi setiap faktor bobot dikalikan evaluasi faktor, seperti dibawah ini :

$$
\begin{array}{ll}
\text { Alternatif Siswa } 1 & =(0.6 \times 80)+(0.3 \times 75)+(0.1 \times 0) \\
& =48+22,5+0 \\
& =70,5 \\
\text { Alternatif Siswa } 2 & =(0.6 \times 60)+(0.3 \times 80)+(0.1 \times 60) \\
& =36+24+6 \\
& =66
\end{array}
$$

Tabel 4.3 Hasil Keputusan

\begin{tabular}{|c|c|c|c|}
\hline No & Nama & Total Bobot Evaluasi & Status \\
\hline 1 & Siswa 1 & 70,5 & IPA \\
\hline 2 & Siswa 2 & 66 & IPS \\
\hline
\end{tabular}

\title{
4.2 Perhitungan Metode Simple Additive Weighting
}

Dalam metode Simple Additive Weighting (SAW) terdapat kriteria yang dibutuhkan untuk proses perhitungan nantinya. Dalam kasus ini ada kriteria yang akan digunakan untuk proses pengambilan keputusan menentukan jurusan. Kriteria-kriteria tersebut adalah :
a. Nilai UN Bahasa Indonesia
b. Nilai UN Bahasa Inggris
c. Nilai UN Matematika
d. Nilai UN IPA
e. Nilai Psikotes
f. Minat

Rating kecocokan setiap alternative (penilaian) pada setiap kriteria yaitu : Sangat Baik (SB), Baik (B), Cukup (C), Kurang (K), dan Sangat Kurang (SK).

Tabel 4.4 Rating Kecocokan Dari Data Awal

\begin{tabular}{|l|l|l|l|l|l|l|}
\hline Alternatif & Nilai Un & Nilai Un & Nilai UN & Nilai UN & Nilai Tes & Minat \\
\hline
\end{tabular}




\begin{tabular}{|c|c|c|c|c|c|c|}
\hline & $\begin{array}{c}\text { Bahasa } \\
\text { Indonesia }\end{array}$ & $\begin{array}{c}\text { Bahasa } \\
\text { Inggris }\end{array}$ & Matematika & IPA & Psikologi & \\
\hline A1 & 65 & 81 & 70 & 80 & 70 & SM \\
\hline A2 & 79 & 75 & 70 & 73 & 60 & M \\
\hline A3 & 60 & 72 & 75 & 70 & 60 & C \\
\hline A4 & 70 & 70 & 81 & 70 & 95 & TM \\
\hline A5 & 76 & 75 & 75 & 81 & 80 & TM \\
\hline
\end{tabular}

Tabel 4.5 Rating Kecocokan Dari Alternatif

\begin{tabular}{|c|c|c|c|c|c|c|}
\hline Alternatif & C1 & C2 & C3 & C4 & C5 & C6 \\
\hline A1 & 2 & 4 & 2 & 3 & 1 & 5 \\
\hline A2 & 3 & 3 & 2 & 3 & 1 & 4 \\
\hline A3 & 1 & 3 & 3 & 2 & 1 & 3 \\
\hline A4 & 2 & 2 & 4 & 2 & 3 & 1 \\
\hline A5 & 3 & 3 & 3 & 4 & 2 & 1 \\
\hline
\end{tabular}

Setelah mendapat kan nilai dari tabel rating kecocokan dari alternatif maka kita dapat menentukan matriks keputusan (matriks X).

$$
X \quad\left\{\begin{array}{llllll}
2 & 4 & 2 & 3 & 1 & 5 \\
3 & 3 & 2 & 3 & 1 & 4 \\
1 & 3 & 3 & 2 & 1 & 3 \\
2 & 2 & 4 & 2 & 3 & 1 \\
3 & 3 & 3 & 4 & 2 & 1
\end{array}\right\}
$$

Langkah selanjutnya dalam metode Simple Additive Weighting (SAW) adalah melakukan normalisasi matriks keputusan $\mathrm{X}$ dengan cara menghitung nilai rating kinerja ternormalisasi (Rij) dari alternatif ( $\mathrm{Ai})$ pada kriteria $(\mathrm{Cj})$.

Sebagai contoh penulis akan melakukan perhitungan untuk R11, R12, R21, dan R22.

$$
\begin{aligned}
& \mathrm{R} 11=\frac{2}{\operatorname{Maks}(2,3,1,2,3)}=\frac{2}{3}=0,66 \\
& \mathrm{R} 12=\frac{3}{\operatorname{Maks}(2,3,1,2,3)}=\frac{3}{3}=1 \\
& \mathrm{R} 21=\frac{4}{\operatorname{Maks}(4,3,3,2,3)}=\frac{4}{4}=1 \\
& \mathrm{R} 22=\frac{3}{\operatorname{Maks}(4,3,3,2,3)}=\frac{3}{4}=0,75
\end{aligned}
$$

Dari perhitungan persamaan diatas., maka di dapat sebuah nilai matriks ternormalisasi (R) yaitu sebagai berikut :

Tabel 4.19 Hasil Normalisasi

\begin{tabular}{|c|c|c|c|c|c|}
\hline 0,66 & 1 & 0,5 & 0,75 & 0,33 & 1 \\
\hline 1 & 0,75 & 0,5 & 0,75 & 0,33 & 0,8 \\
\hline 0,33 & 0,75 & 0,75 & 0,5 & 0,33 & 0,6 \\
\hline 0,66 & 0,5 & 1 & 0,5 & 1 & 0,2 \\
\hline 1 & 0,75 & 0,75 & 1 & 0,66 & 0,2 \\
\hline
\end{tabular}

Setelah didapatkan nilai ternormalisasi maka dilanjutkan dengan menghitung nilai preferensi (Vi). Nilai $\mathrm{V}$ diperoleh dari penjumlahan dari perkalian elemen baris matrik ternormalisasi (R) dengan bobot preferensi (W) yang bersesuaian elemen kolom matrik (W). 
Nilai total Vi untuk jurusan dapatdihitung dengan nilai perkalian pada tabel 4.11 dengan nilai bobot $\mathrm{W}$ jurusan IPA $=\left\{\begin{array}{llllll}0,8 & 0,8 & 1 & 1 & 0,8 & 1\end{array}\right\}$ dengan matriks R. Sebagai contoh penulis akan menghitung nilai V1.

$$
\begin{aligned}
\mathrm{V} 1 & =(0,8)(0,66)+(0,8)(1)+(1)(0,5)+(1)(0,75)+(0,8)(0,33)+(1)(1) \\
& =0,52+0,8+0,5+0,75+0,26+1 \\
& =3,83
\end{aligned}
$$

Tabel 4.20 Hasil perhitungan Nilai V

\begin{tabular}{|c|c|}
\hline Alternatif & Nilai Total \\
\hline V1 & 3,83 \\
\hline V2 & 3,71 \\
\hline V3 & 2,97 \\
\hline V4 & 3,42 \\
\hline V5 & 3,87 \\
\hline
\end{tabular}

Setelah melakukan perhitungan Vi maka didapatkan lah hasil akhir dari penentuan jurusan siswa. Setiap siswa yang memiliki nilai total diatas dari $>3,00$ maka status jurusan IPA dan siswa dengan nilai total $<3.00$ status jurusan IPS.

Tabel 4.21 Hasil Keputusan

\begin{tabular}{|c|c|c|}
\hline Alternatif & Nilai Total & Status \\
\hline A1 & 3,83 & IPA \\
\hline A2 & 3,71 & IPA \\
\hline A3 & 2,97 & IPS \\
\hline A4 & 3,42 & IPA \\
\hline A5 & 3,87 & IPA \\
\hline
\end{tabular}

\section{Implementasi}

Implementasi sistem bertujuan untuk melihat apakah sistem yang dirancang sudah sesuai dengan apa yang diinginkan atau belum. Setelah dilakukannya pengujian dan implementasi, kualitas sebuah sistem akan dapat dilihat. Berikut adalah implementasi dari perancangan aplikasi sistem pendukung keputusan yang dibuat penulis

1. Halaman pertama yang muncul ketika diakses adalah halaman login.

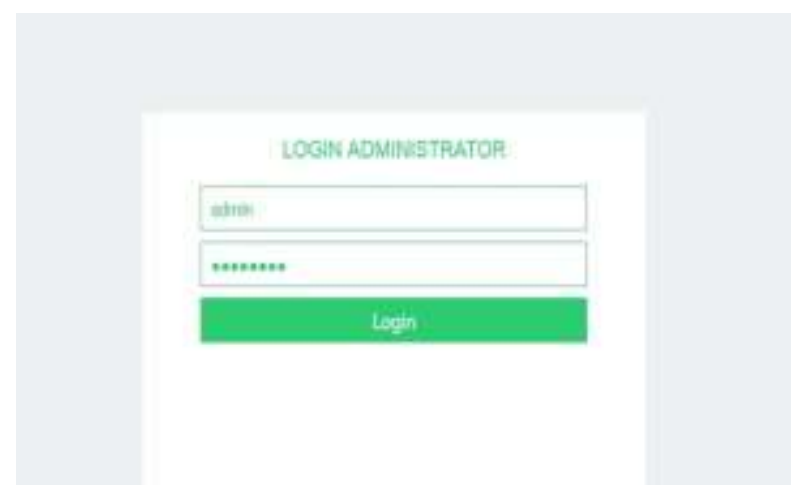

Gambar 5.1 Interface Halaman Login

2. Setelah berhasil login maka akan muncul interface dari beranda (home). 


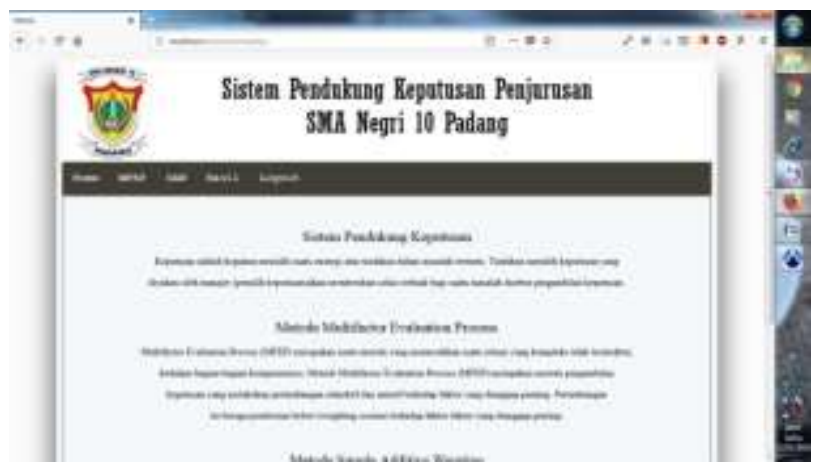

Gambar 5.2 Interface Halaman Home

3. Untuk menentukan penjurusan dapat dilakukan dua mtode yang telah diangkat oleh penulis yaitu metode Multifactor Evaluation Process dan metode Simple Additive Weihting.

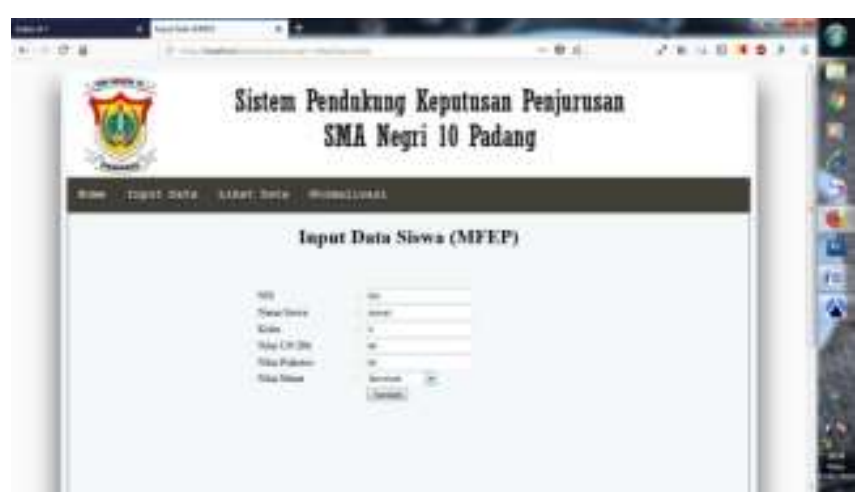

Gambar 5.3 Interface Halaman Input Data Metode Multifactor Evaluation Process

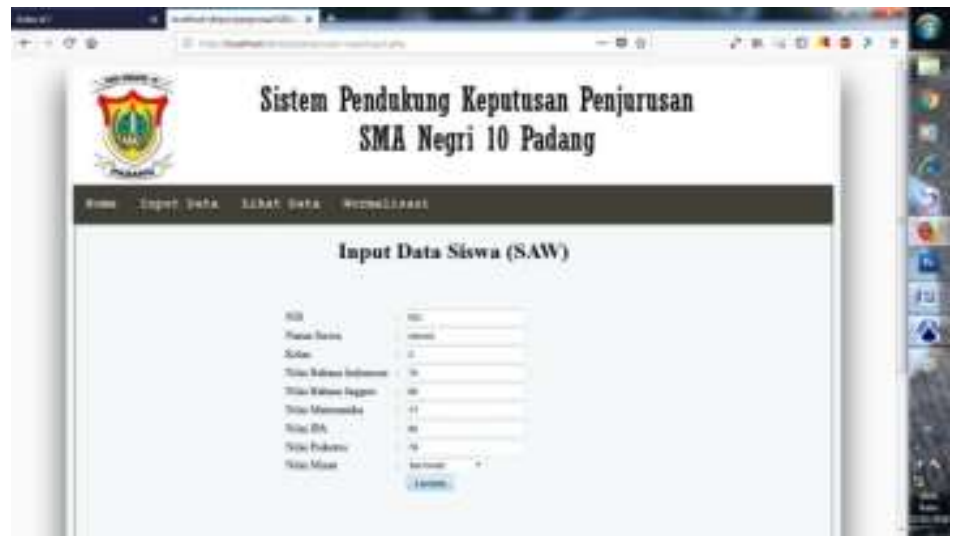

Gambar 5.4 Interface Halaman Input Data Metode Simple Additive Weihting

4. Tampilan untuk melihat hasil dari proses sistem pendukung keputusan dari masing-masing metode. 


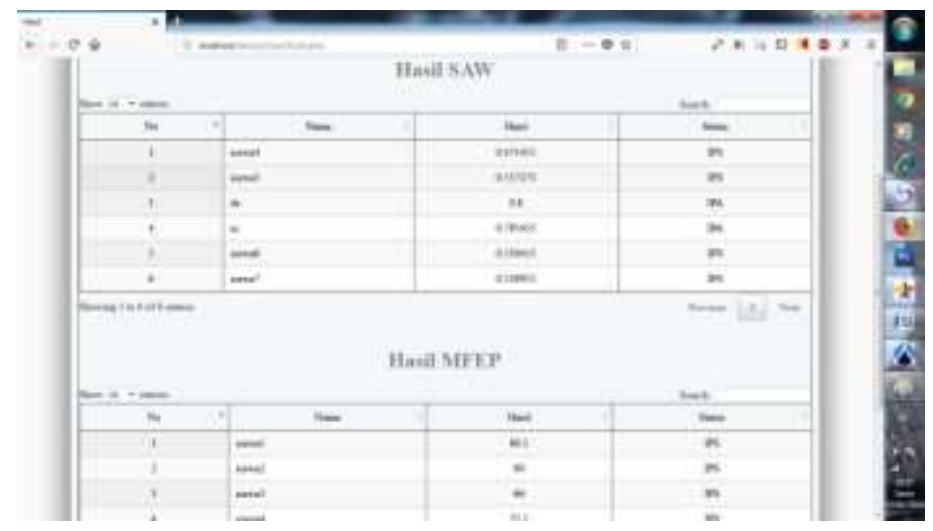

Gambar 5.5 Interface Halaman Hasil

Setelah melakukan implementasi dan pengujian sistem, maka dapat disimpulkan bahwa aplikasi sistem pendukung keputusan yang dibuat oleh penulis berjalan dengan semestinya dan sesuai dengan perancangan.

5. Terakhir adalah melakukan pencetakan hasil dari proses sistem pendukung keputusan, agar dapat diserahkan kepada kepala sekolah.

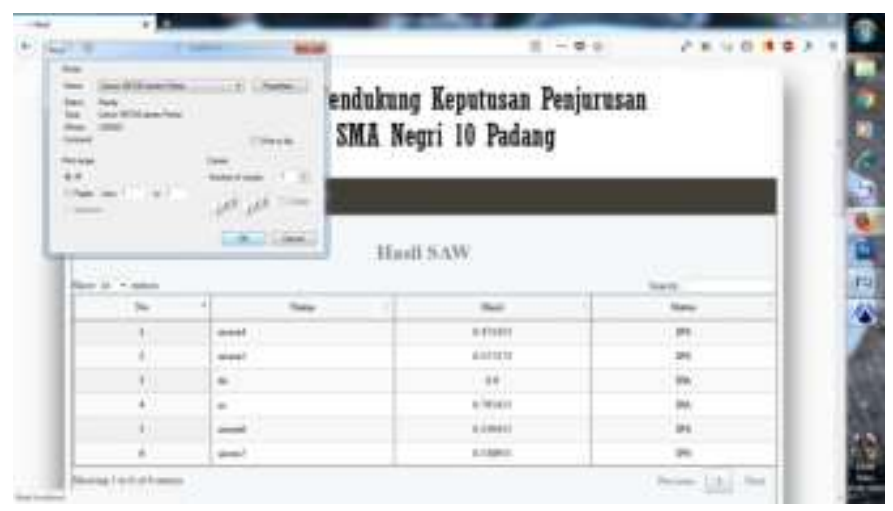

Gambar 5.10 Print Hasil

\section{Kesimpulan}

Kesimpulan hasil penelitian:

a. Aplikasi ini terbukti mampu mempermudah pihak terkait dalam melakukan proses seleksi dengan menggunakan metode Multifactor Evaluation Process dan metode Simple Additive Weighting.

b. Sistem pendukung keputusan ini dirancang denga sistem komputerisasi menggunakan program PHP serta database dengan menggunakan MySQL.

c. Dengan menggunakan metode Multifactor Evaluation Process dan metode Simple Additive Weighting hasil akhir perhitungan berupa status jurusan yang menetukan jurusan dari para siswa.

d. Dengan menggunakan metode Multifactor Evaluation Process dan metode Simple Additive Weighting kita dapat membandingkan hasil yang di dapat. 


\section{Daftar Pustaka}

[1] Iqbal Maulana, Yana. "Perancangan Perangkat Lunak Sistem Infrmasi Pendataan Guru Dan Sekolah (SINDARU) Pada dinas Pendidikan Kota Tangerang Selatan". Yogyakarta: Jurnal Pilar Nusantara Mandiri (2017).

[2] Rosa AS dan M. Shalahuddin. "Rekayasa Perangkat Lunak Terstruktur Dan Berorientasi Objek". Bandung: INFORMATIKA (2015).

[3] Pressman, Roger S. "Pendekatan Praktisi Rekayasa Perangkat Lunak Edisi 7". Yogyakarta: Andi (2010).

[4] Kadir, Abdul. “Algoritma dan Pemograman Menggunakan Java”. Yogyakarta: Andi Offset (2012).

[5] Prayitno, Agus dan Yulia Safitri. "Pemanfaatan Sistem Informasi Perpustakaan Digital Berbasis Website Untuk Para Penulis". Jakarta Timur: Indonesian Journal on Software Engineering (2015).

[6] Muchtar, Agus dkk. "Peranccangan Database Management Systema Penjualan Pada PT. Samafitro Cabang Bandung Dengan Menggunakan Software Microsoft Visual Basic 6.0 Dan Microsoft SQ1 Server 2000 Berbasis Client Server". Bandung: Jurnal Komputerisasi Akuntansi (2010).

[7] Ramadhani, Syaifudin dkk. "Rancang Bangun Sistem Informasi Geografis Layanan Kesehatan Di Kecamatan Lamongan Dengan PHP MySql”. Lamongan: Jurnal Teknika Vol. 5 No. 2 (2013).

[8] Komputer, Wahana. "Membangun Web Interaktif dengan Adobe Dreamewaever CS5, PHP dan MySQL". Semarang: Andi Yogyakarta (2012).

[9] Oktavian, Diar Puji. "Membuat Website Powerfull PHP”. Yogyakarta: MediaKom (2013).

[10] Ari Prabowo, faisal dan Mamay Syani. "Sistem Informasi Pengolahan Sertifikat Berbasis Web Divisi Training Seamolec". Bandung: Jurnal Masyarakat Informatika Indonesia (2017).

[11] Sutabri, Tata. “Analisis Sistem Informasi”. Yogyakarta: Andi (2012).

[12] Khaidir, Ahmad. "Sistem Pendukung Keputusan Penyeleksian Calon Siswa Baru di SMA Negri 1 Badar Dengan Metode MFEP”. Medan: Jurnal Pelita Informatika Budi Darma Vol VI No. 3 (2014).

[13] Wulan Sari, Bety. "Perbandingan Metode Profile Matcing Dan Simple Additive Weighting Pada Penentuan Jurusan Siswa Kelas X SMA N 2 Nagalik". Yogyakarta: Jurnal Ilmiah DASI (2015).

[14] Cintya Resti, Nalsa. "Penerapan Metode Simple Additive Weighting (SAW)Pada Sistem Pendukung Keputusan Pemilihan Lokasi Untuk Cabang Baru Toko Pakan UD Indo Multi Fish". Kediri: Jurnal Intensif (2014). 